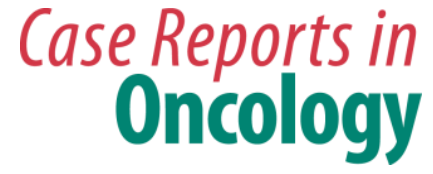

Case Rep Oncol 2019;12:742-748

DOI: 10.1159/000502856

Published online: September 27, 2019

2019 The Author(s)

Published by S. Karger AG, Basel

www.karger.com/cro

This article is licensed under the Creative Commons Attribution-NonCommercial 4.0 International License (CC BY-NC) (http://www.karger.com/Services/OpenAccessLicense). Usage and distribution for commercial purposes requires written permission.

\title{
Atypical Presentation of a Medullary Thyroid Carcinoma Producing Acth and Serotonin
}

\author{
Mariana Ferreira ${ }^{a} \quad$ Christianne Toledo de Souza Leal ${ }^{b}$ \\ Lize Vargas Ferreira $^{b}$ Danielle Guedes Andrade Ezequiel ${ }^{b}$ \\ Mônica Barros Costab
}

aServiço de Endocrinologia, Hospital Universitário da Universidade Federal de Juiz de Fora, Juiz de Fora, Brazil; ${ }^{b}$ Departamento de Clínica Médica da Faculdade de Medicina da Universidade Federal de Juiz de Fora, Juiz de Fora, Brazil

\section{Keywords}

Thyroid cancer $\cdot$ Medullary $\cdot$ ACTH syndrome $\cdot$ Ectopic $\cdot$ Thyroid neoplasm

\begin{abstract}
Medullary carcinoma accounts for about $5 \%$ of all thyroid malignancies. The tumor may produce other hormones in addition to calcitonin that typically occurs in the presence of distant metastases. The aim of this report is to present a case of invasive medullary thyroid carcinoma producing ACTH and serotonin. A male patient sought medical attention due to facial plethora and distal paresthesia. On thyroid ultrasound, he presented a hypoechoic nodule measuring $6.7 \times 3.2 \times 3.5 \mathrm{~cm}$, with punctate calcifications and central vascular pattern. The chest computed tomography showed an extensive solid lesion with epicenter in the superior mediastinum and absence of a cleavage plane with the left thyroid lobe. The lesion extended from the glottic area to the lower portion of the trachea and invaded esophagus, posterior tracheal wall, and left jugular. The patient presented hyperglycemia, hypokalemia, increased free urinary cortisol, calcitonin, ACTH and 5-hydroxyindoleacetic acid levels. The nodule cytological
\end{abstract}




\section{Case Reports in Oncology}

Ferreira et al.: Atypical Presentation of a Medullary Thyroid Carcinoma Producing Acth and Serotonin

examination obtained by fine-needle aspiration was inconclusive, and the open biopsy confirmed the diagnosis of medullary thyroid carcinoma. Due to the advanced disease stage and increased risk of large caliber vessels injury in case of surgery, local chemotherapy and radiotherapy were recommended. With this report, we want to draw attention to an unusual association between advanced medullary thyroid carcinoma with an aggressive course and ectopic production of ACTH and serotonin.

(C) 2019 The Author(s)

Published by S. Karger AG, Basel

\section{Introduction}

Medullary thyroid carcinoma (MTC) is a neuroendocrine tumor derived from C cells that is responsible for approximately $5 \%$ of the gland malignancies, and most of them occur sporadically. Approximately $30 \%$ of these tumors are associated with autosomal dominant hereditary disease, either multiple endocrine neoplasia (MEN) types 2A and 2B or familial MTC [1]. The 10-year survival rate for MTC varies from 75 to $85 \%$ even in the presence of distant metastases, which may occur in $20 \%$ of the cases at diagnosis [2].

The $\mathrm{C}$ cells secrete neuropeptides, such as calcitonin and carcinoembryonic antigen (CEA), that are useful tumor markers in clinical practice to diagnose and monitor MTC [3]. These cells may also produce other hormones that rarely cause clinical manifestations, but may secret them in large amount in the presence of distant metastases. Among these hormones, ACTH and CRH are the most frequently secreted and may be associated with Cushing syndrome (CS). About 2-6\% of the cases of CS due to ectopic ACTH secretion are associated with ACTH secretion by an MTC [4-6]. Other hormones that may be produced by an MTC are serotonin, somatostatin, pro-opiomelanocortin, vasoactive intestinal peptide, chromogranin A, amyloid, gastrin-releasing peptide, and histamine [4, 7].

There are currently only 50 cases in the literature describing an ACTH-secreting MTC leading to CS, and the reports of MTC cases associated with serotonin secretion are even less frequent $[8,9]$. The aim of this report is to present a rare case of invasive MTC producing ACTH and serotonin.

\section{Case Report}

A 54-year-old male patient with hypertension diagnosed one year before sought medical attention due to facial plethora and distal paresthesia that had progressed over the previous eight months. During the physical examination, he presented a full-moon face, facial plethora, and a nodule at the cervical area.

The patient had been referred from another institution in which thyroid ultrasound and color Doppler were performed. These tests showed a hypoechoic nodule in the left thyroid lobe measuring $6.7 \times 3.2 \times 3.5 \mathrm{~cm}$, with punctate calcifications and a predominantly central vascular pattern. A fine-needle aspiration biopsy (FNAB) of the cervical nodule showed abundant pleomorphic cells with round and hyperchromatic nuclei, gross chromatin, and occasional evident nucleoli. These cells ranged in shape from plasmacytoid to fusiform, had ample cytoplasm and sporadic long extensions, and were either loose or gathered in irregular 


\section{Case Reports in Oncology}

Case Rep Oncol 2019;12:742-748

DOI: $10.1159 / 000502856$

(c) 2019 The Author(s). Published by S. Karger AG, Basel www.karger.com/cro

Ferreira et al.: Atypical Presentation of a Medullary Thyroid Carcinoma Producing Acth and Serotonin

groups, with molding and overlap. Bizarre, multinucleated cells with atypical mitoses were also observed. A pinkish, glassy material was observed on the background, along with some leukocytes and erythrocytes.

The neck computed tomography (CT) showed a tumoral mass invading the posterior wall of the trachea, with absence of a cleavage plane between the mass and the esophagus, invasion of prevertebral muscles, and contact with thoracic vertebral bodies. The chest CT showed a large heterogeneous solid lesion, with the epicenter in the left superior mediastinum, absence of a cleavage plane between the lesion and the left lobe of the thyroid, and the largest anteroposterior diameter of $5.0 \mathrm{~cm}$. The lesion extended from the glottic area to the lower portion of the trachea, invading esophagus, posterior wall of the trachea, and left jugular. Enlarged lymph nodes in the mediastinum and cervical groups were also observed.

During hospitalization, the patient showed a persistent increase in blood glucose levels that reached $300 \mathrm{mg} / \mathrm{dL}$, hypokalemia refractory to intravenous potassium, and increased urinary free cortisol levels. The plasma cortisol levels after overnight suppression with $1 \mathrm{mg}$ of dexamethasone were $26.8 \mu \mathrm{g} / \mathrm{dL}$, reinforcing the suspicion of CS, which was confirmed by plasma ACTH measurement of $109 \mathrm{pg} / \mathrm{mL}$. The levels of serum calcitonin and urinary 5-hydroxyindoleacetic acid were also determined to screen for MTC and associated carcinoid syndrome. To exclude the diagnosis of pheochromocytoma, the levels of urinary catecholamines, metanephrines, and normetanephrines were also measured. Table 1 shows the main laboratory tests performed during hospitalization.

Due to the occurrence of hypercortisolism, ketoconazole $200 \mathrm{mg}$ twice a day was prescribed, but three days later had to be suspended due to an increase in transaminases levels thrice above the reference value. Insulin therapy was started and potassium chloride replaced (oral and intravenous). Since the nodule cytological examination obtained by FNAB could not offer a conclusive diagnosis, an open biopsy of the lesion was performed. The carotid artery showed extensive invasion by the tumor and was lacerated during the procedure, requiring rapid intervention. The histopathological examination of the biopsy material indicated a neoplasm, which was confirmed as an MTC by immunohistochemistry.

After discussing the case with a multidisciplinary team, it was recommended radiotherapy and chemotherapy with doxorubicin $38 \mathrm{mg} /$ week for five weeks, and cisplatin $40 \mathrm{mg} / \mathrm{m}^{2}$ to a total dose of $76 \mathrm{mg}$ every 21 days. During control echocardiography, the patient presented ejection fraction of $51 \%$, and doxorubicin was suspended. He progressed with gradual clinical improvement and the tumor volume reduced. However, due to severe peripheral neuropathy, cisplatin was suspended and replaced by sunitinib $50 \mathrm{mg} /$ day associated with prednisone $20 \mathrm{mg}$ /day. Sunitinib induced substantial toxicity, with an increase in serum glutamate-pyruvate transaminase (SGPT) and gamma-glutamyl transferase (GGT) twice above the reference value, requiring dose reduction to $25 \mathrm{mg} /$ day. The abdominal CT performed six months after starting sunitinib therapy detected hepatic metastases, the largest one with $9.3 \times 6.3 \mathrm{~cm}$. Afterwards, the multidisciplinary team decided to suspend the medication and maintain clinical support. The patient died 23 days later. 


\section{Case Reports in Oncology}

\section{Discussion}

In the present report, we described a case of atypical presentation of MTC producing serotonin and ACTH with consequent hypercortisolism.

Approximately $70 \%$ of the MTC cases are sporadic. In these cases, the most common initial presentation is the presence of a solitary thyroid nodule, associated or not with cervical lymphadenopathy. The diagnosis is commonly established by FNAB of the nodule, in which amyloid is observed along with positivity for calcitonin, CEA, and chromogranin A on immunohistochemistry $[3,4]$.

The reported case shows an MTC with an unusual presentation producing several hormones. In addition, the patient had metastases in cervical lymph nodes and significant extrathyroidal invasion. As commonly known, MTC may spread to regional lymph nodes and, via hematogenous routes, to liver, bones, and lungs $[3,4]$.

The FNAB showed the presence of neoplastic fusiform cells with nuclear pleomorphism but amyloid deposits or another finding that could inform about the primary site of the lesion were not present. Under these circunstances, the open biopsy followed by immunohistochemistry was performed.

Among the several substances occasionally produced by tumor cells in MTC chromogranin A, CEA, calcitonin gene-related peptides, $\mathrm{CRH}, \mathrm{ACTH}$, somatostatin, and vasoactive intestinal peptide are the most cited in the literature. Ectopic production of insulin, glucagon, and PTH-related peptide are rarely reported $[3,4]$. Also, the thyroid C cells carry out synthesis and/or uptake of amines. The presence of 5-hydroxytryptamine (serotonin) in patients with MTC has rarely been described $[8,10]$. Although symptoms related to serotonin secretion such as cervicothoracic flushing, secretory diarrhea and heart failure [11] were not present in this case, the 5-hydroxyindoleacetic acid assay was performed to rule out the presence of carcinoid tumor as the cause of CS presented by the patient. Calcitonin, which rarely causes clinical manifestations, is considered the main marker of MTC and is used for diagnosis, staging, post-operative management and prognosis. In this case, there were no manifestations related to the increase in calcitonin. Due to the patient's high calcitonin levels, the occurrence of metastases was suspected. Levels of calcitonin greater than $400 \mathrm{pg} / \mathrm{mL}$ are strongly suggestive of metastases and require appropriate screening $[3,4]$. The present patient had an advanced disease with soft tissue invasion and distant metastases.

Secretion of CRH or ACTH, as in the case presented here, may result in CS, often with hypokalemia as the initial presentation, which is associated with lower survival due to the progressive characteristic of the cancer [4]. The association between CS and cancer was first described in 1928 in a patient with oat-cell lung cancer [12]. In a recent study, lung cancer was the most frequent type of malignant neoplasm associated with CS, responsible for $45 \%$ of the cases. Bronchial carcinoids, in turn, are responsible for about $25 \%$ of the cases of CS associated with ectopic hormone secretion, followed by tumors of the thymus $(11 \%)$ and pancreas $(8 \%)$, neuroendocrine tumors associated with MTC $(6 \%)$, and adrenal pheochromocytomas $(5 \%)$ [12]. Medullary thyroid cancer is responsible for only $2-6 \%$ of the cases of CS due to ectopic secretion [4].

In a retrospective study that included 1,640 adult patients with MTC, Barbosa et al. have described ectopic MTC-related Cushing syndrome in 10 cases, most of them of male gender, as the case presented here and in other reports $[6,8]$. When compared with patients with 
Cushing disease, those with CS due to ectopic ACTH secretion show higher levels of ACTH and cortisol and a more rapid progression of the symptoms, as in the patient presented here [12]. The clinical symptoms of CS may be remarkable. Like others $[6,8,13,14]$ the patient described here presented severe symptoms of hypercortisolism such as hypertension, cushingoid features, hyperglycemia and hypokalaemia. Regarding the evolution of the disease, most of the cases in the literature had distant metastases $[6,8]$ bad course and most of them died, as a consequence of CS complications or due to evolution of MTC, similar to the patient presented here $[8,13]$.

As for the treatment of MTC, the stage of the disease is the most important information to define management. In advanced stages, surgery should not be extensive, since it does not cure, and total thyroidectomy is recommended with removal of the visible neoplastic tissue to protect the airway and control the disease locally [3]. In the case described here clinical treatment with local chemotherapy and radiotherapy was chosen considering the extensive adhesion and friability of the neoplastic tissue, which was associated with a high risk of injury of large caliber vessels, such as the carotid artery. The tyrosine kinase inhibitors, especially vandetanib, are the first-line therapy for advanced MTC [4]. Nella et al. published the remission of MTC in an adolescent using vandetanib [14] and Baudry et al. have reported the reversal of CS by vandetanib use in a 58-year old man with a metastatic, ACTH-producing MTC who presented severe side-effects following the use of ketoconazole, similar to our patient [15]. However, due to the unavailability of this drug from the public health system, the treatment was carried out with conventional chemotherapy drugs. The patient presented cardiotoxicity with doxorubicin, neurotoxicity with cisplatin, and hepatotoxicity with sunitinib, progressing to death. In the same way, Barbosa et al. have reported that $80 \%$ of patients with CMT associated with CS did not survive more than 12.8 months after the diagnosis of CS [8].

With the present case report, we intend to draw attention to an unusual MTC producing ACTH and serotonin, with a late presentation and aggressive course.

\section{Statement of Ethics}

The family of the patient have given their written informed consent to publish the case.

\section{Disclosure Statement}

The authors declare to have no conflicts of interest related to the present study.

\section{Funding Sources}

No funding was received. 


\section{Author Contributions}

All the authors contributed for the paper, including writing and revising it. All authors read and approved the final manuscript.

\section{References}

1 Hoff AO, Hoff PM. Medullary thyroid carcinoma. Hematol Oncol Clin North Am. 2007 Jun;21(3):475-88.

2 Randolph GW, Maniar D. Medullary carcinoma of the thyroid. Cancer Contr. 2000 May-Jun;7(3):253-61.

3 Maia AL, Siqueira DR, Kulcsar MA, Tincani AJ, Mazeto GM, Maciel LM. Diagnóstico, tratamento e seguimento do carcinoma medular de tireoide: recomendações do Departamento de Tireoide da Sociedade Brasileira de Endocrinologia e Metabologia. Arq Bras Endocrinol Metabol. 2014;58(7):667-700.

4 Wells SA Jr, Asa SL, Dralle H, Elisei R, Evans DB, Gagel RF, et al; The American Thyroid Association Guidelines Task Force on Medullary Thyroid Carcinoma. Revised American Thyroid Association Guidelines for the Management of Medullary Thyroid Carcinoma. Thyroid. 2015 Jun;25(6):567-610.

5 Ilias I, Torpy DJ, Pacak K, Mullen N, Wesley RA, Nieman LK. Cushing's syndrome due to ectopic corticotropin secretion: twenty years' experience at the National Institutes of Health. J Clin Endocrinol Metab. 2005 Aug;90(8):4955-62.

6 Smallridge RC, Bourne K, Pearson BW, Van Heerden JA, Carpenter PC, Young WF. Cushing's syndrome due to medullary thyroid carcinoma: diagnosis by proopiomelanocortin messenger ribonucleic acid in situ hybridization. J Clin Endocrinol Metab. 2003 Oct;88(10):4565-8.

7 Pacini F, Castagna MG, Cipri C, Schlumberger M. Medullary thyroid carcinoma. Clin Oncol (R Coll Radiol). 2010 Aug;22(6):475-85.

8 Barbosa SL, Rodien P, Leboulleux S, Niccoli-Sire P, Kraimps JL, Caron P, et al.; Groupe d'Etude des Tumeurs Endocrines. Ectopic adrenocorticotropic hormone-syndrome in medullary carcinoma of the thyroid: a retrospective analysis and review of the literature. Thyroid. 2005 Jun;15(6):618-23.

9 Pitoia F, Bueno F, Schmidt A, Lucas S, Cross G. Rapid response of hypercortisolism to vandetanib treatment in a patient with advanced medullary thyroid cancer and ectopic Cushing syndrome. Arch Endocrinol Metab. 2015 Aug;59(4):343-6.

10 Hocevar M, Bergant D, Auersperg M, Golouh R. Medullary carcinoma of the thyroid with serotonin production and carcinoid-like syndrome. Eur J Surg Oncol. 2001 Mar;27(2):219-22.

11 Sarrouilhe D, Clarhaut J, Defamie N, Mesnil M. Serotonin and cancer: what is the link? Curr Mol Med. 2015;15(1):62-77.

12 Isidori AM, Lenzi A. Ectopic ACTH syndrome. Arq Bras Endocrinol Metabol. 2007 Nov;51(8):1217-25.

13 Mure A, Gicquel C, Abdelmoumene N, Tenenbaum F, Francese C, Travagli JP, et al. Cushing's syndrome in medullary thyroid carcinoma. J Endocrinol Invest. 1995 Mar;18(3):180-5.

14 Nella AA, Lodish MB, Fox E, Balis FM, Quezado MM, Whitcomb PO, et al. Vandetanib successfully controls medullary thyroid cancer-related Cushing syndrome in an adolescent patient. J Clin Endocrinol Metab. 2014 Sep;99(9):3055-9.

15 Baudry C, Paepegaey AC, Groussin L. Reversal of Cushing's syndrome by vandetanib in medullary thyroid carcinoma. N Engl J Med. 2013 Aug;369(6):584-6. 


\section{Case Reports in Oncology}

\begin{tabular}{l|l}
\hline Case Rep Oncol 2019;12:742-748 \\
\hline DOI: 10.1159/000502856 & $\begin{array}{l}\text { (c) 2019 The Author(s). Published by S. Karger AG, Basel } \\
\text { www.karger.com/cro }\end{array}$
\end{tabular}

Ferreira et al:: Atypical Presentation of a Medullary Thyroid Carcinoma Producing Acth and Serotonin

Table 1. Main laboratory tests performed during hospitalization

\begin{tabular}{lcc}
\hline Tests & Results & Reference values \\
\hline Calcitonin, $\mathrm{pg} / \mathrm{mL}^{*}$ & $1,543.0$ & $<18.2$ \\
Free urinary cortisol, $\mu \mathrm{g} / 24 \mathrm{~h}^{*}$ & $7,238.5$ & $28.5-213.7$ \\
Plasma cortisol, $\mu \mathrm{g} / \mathrm{dL} *$ & 26.8 & $<1.8$ \\
$\mathrm{ACTH}, \mathrm{pg} / \mathrm{mL}^{*}$ & 109.0 & $<46.0$ \\
5-hydroxyindoleacetic acid, $\mathrm{mg} / 24 \mathrm{~h}^{* *}$ & 20.5 & $2.0-9.0$ \\
Urinary catecholamines, $\mu \mathrm{g} / 24 \mathrm{~h}^{* *}$ & 365.0 & $80.0-500.0$ \\
Total urinary metanephrines, $\mu \mathrm{g} / 24 \mathrm{~h}^{* *}$ & 93.0 & $<1,000.0$ \\
Urinary normetanephrines, $\mu \mathrm{g} / 24 \mathrm{~h}^{* *}$ & 43.0 & $<390.0$ \\
Urinary metanephrines, $\mu \mathrm{g} / 24 \mathrm{~h}^{* *}$ & 12.0 & $<320.0$ \\
\hline
\end{tabular}

* Chemiluminescence immunoassay; ${ }^{* *}$ high-performance liquid chromatography (HPLC). 